
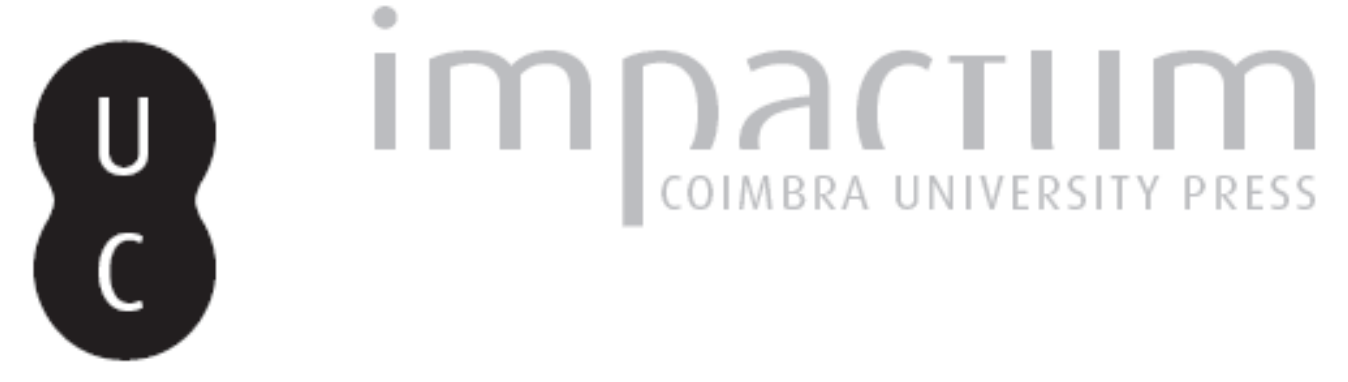

\title{
Uma união de factos contemporânea: Jornalismo e situações de risco
}

Autor(es): $\quad$ Figueira, João

Publicado por: Associação Portuguesa de Riscos, Prevenção e Segurança

URL persistente:

URI:http://hdl.handle.net/10316.2/36214

DOI:

DOI:http://dx.doi.org/10.14195/1647-7723_14_1

Accessed : $\quad$ 26-Apr-2023 08:43:08

A navegação consulta e descarregamento dos títulos inseridos nas Bibliotecas Digitais UC Digitalis, UC Pombalina e UC Impactum, pressupõem a aceitação plena e sem reservas dos Termos e Condições de Uso destas Bibliotecas Digitais, disponíveis em https://digitalis.uc.pt/pt-pt/termos.

Conforme exposto nos referidos Termos e Condições de Uso, o descarregamento de títulos de acesso restrito requer uma licença válida de autorização devendo o utilizador aceder ao(s) documento(s) a partir de um endereço de IP da instituição detentora da supramencionada licença.

Ao utilizador é apenas permitido o descarregamento para uso pessoal, pelo que o emprego do(s) título(s) descarregado(s) para outro fim, designadamente comercial, carece de autorização do respetivo autor ou editor da obra.

Na medida em que todas as obras da UC Digitalis se encontram protegidas pelo Código do Direito de Autor e Direitos Conexos e demais legislação aplicável, toda a cópia, parcial ou total, deste documento, nos casos em que é legalmente admitida, deverá conter ou fazer-se acompanhar por este aviso.

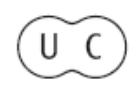




\section{territorium}


pp. $5-9$

\section{UMA UNIÃO DE FACTOS CONTEMPORÂNEA: JORNALISMO E SITUAÇÕES DE RISCO*}

\section{RESUMO}

A escrita jomalística é por natureza conflitual. Gosta do confronto e, nesse sentido, dramatiza os acontecimentos, criandb um clima de tensão com o dbjectivo de tocar o leitor e o prender ao texto. O risco, por seu lado, tomou-se num conceito central do debate público. Como é que as sociedades democráticas contemporâneas devem lidar com tais situações? Um dos caminhos é o exercício da verdade, da abertura e da confiança entre todas as actores envolvidas no processo.

Palavras chave: Escrita jomalística, conflital, risco, dramatizar acontecimentos.

\section{ABSTRACT}

Jamalismandrisk situations: a contemporary fact union. The jam malistic wey of writing is by itself quamelsome. It has a good relationship with dramatic events, creating a tense and intense atmosphere. The risk becomes itself a central concept in the public debate. How can the democratic societies face and manage thase realities? Some of the keys are the truth, qpen mind and confidence among all the actors involved.

Key words: Jamalistic wey of writing, quarrelsome, risk, dramatizing events.

\section{RÉSUMÉ}

Uhe union de faits contemporaine: jaumalisme et situations de risques. L'écriture jaumalistique est par nature conflictuelle. Elle aime la confrontation. Elle dramatise en ce sens les événements et crée une atmosphère de tension qui a par bat de taucher le lecteur et de le river au texte. Le risque, de son côté, est devenu un concept central du débat public. Comment les sociétés démocratiques contemporaines doivent-elles réagir face à de telles situations? Une des méthodes est l' exercice de la vérité, de l'averture et de la confiance entre taus les acteurs impliqués dans ce processus.

Mots clé: Écriture jamalistique, conflictuelle, confrontation. 


\section{Introdução}

A imagem e o termo risco são uma expressão de fácil acesso e de grande circulação no território jomalístico.

E, todavia, não deixa de ser interessante notar que todos os títulos mostrados - apesar de construídos em tomo da ideia do risco - jamais se referem às consequências de um qualquer acontecimento concreto.

A alma que os anima é a incerteza e a imprevisibilidade. Talvez a iminência de algo de grave que está para acontecer, isto é, de consequências gravosas, edaí, haver umrisco, palavra esta quemuitas vezes se escreve no lugar de perigo. Uma e autra, no entanto, desfrutam de umnítidb acolhimento no seio do idiona jomalístico. Mas quando às palavras se juntam as acontecimentos, o cenário, do panto de vista das interesses noticiosos, estápróximo da perfeição.

A escrita jomalística, porque é dela que se trata quando abordamos as questões da informação - uma vez que os acontecimentos, trágicos ou divertidos, apenas existem e nos chegam enquanto narrativas possui um elevado grau de conflitualidade. 0 "jomalês", como se diz na gíria, é por natureza conflitual. Isto é, dá-se bem e aultiva o gosto pelo confronto, se possível dramatizando o cenário e criando um clima de tensão cam o dbjectivo de tocar o leitor e oprender ao texto.

Vários teóricos e investigadbres das ciências da commicação, como José Vil lamor, coincidemna ideia de que o jomalista tem o seu próprio idiana, auja característica principal é a agressividade, para com ela chegar mais facilmente ao leitor e assim atrair a sua atenção'.

Por vezes, no entanto, como sucedeu em 2005, em Nova Orleães, os próprios órgãos de comunicação social são apanhados pelas catástrofes, sofrendo na pele os efeitos devastadbres daquil o que, por norma, é o seu campo de daservação e trabalho.

pois bem, no caso do Katrina, tanto o Stm Herald como o The Times Picayrme, com os respectivos edifícios afectados pelo furacão (29/8/05) continuaram a trabalhar, razão pela qual foram, mais tarde, distinguidas como prémio Pul itzer de Jomalismo de Serviço Público - que é o mais prestigiado e apetecível prémio de jomalismo das Estadas Uninidas - pelo papel de resistência e tenacidade que desempenharam.

A mesma catástrofe proporcionou um Pulitzer de fotojomalismo de actualidade ao jomal Dallas Moming News, pelas 20 imagens de dor e desespero de pessoas que tinham perdido tudo. Os dois casos

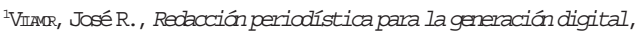
Editorial Universitas, Madrid, 2000, pp.85-86. tipificampapéis diferentes face ao risco eà catástrofe. Os jornais de Nova Orleães, mantendo-se em actividade, deram um exemplo de resistência à adversidade, ao mesmo tempo que usaram os respectivos sites na Intemet para ajudar a pquulação a encontrar familiares desaparecidos ou para saberem as novidades sobre a recuperação dos locais devastados.

O jomal de Dallas, alheio ao jomalismo de proximidade das attros dbis diários, pelo menos neste caso, publicou um conjunto de fotos que mostravama imagem de destruição da cidade e a dor das pessoas afectadas.

Em ambos os casos, no entanto, por força da mediatização do acontecimento, a catástrofe real, acontecida, assumiu as proporções de uma tragédia mediática, em consequência da cobertura de que foi alvo, o que demonstra que, muitas vezes, certos acontecimentos, pela força da sua narração, também tocam os que a ele assistem à distância.

Assim foi com o furacão de Nova Orleães, com o tsunami na Tailândia, com os terramotos no Japão, Turquia ou América Latina ou com a pante de Entre-osRios em Portugal.

\section{Numa sociedade democrática, quem define as situações de risco?}

Através da televisão, meio dominante no actual universo mediático, as imagens e a informação chegam a todo o lado com uma dimensão de espectacularidade que nenhum outro meio de massas consegue. E essa dimensão de espectáculo é, mais do que rumca, levada a patamares notáveis, fruto dos meios técnicos e tecnológicas disponíveis. Se a estes aspectos juntarmos a ideia da transmissão em directo, facilmente observaremos que a TV influencia a nossa visão e interpretação dos acontecimentos, mas, também, ela própria influencia e determina a evolução dos acontecimentos subsequentes à crise au catástrofe que cobre, porque funciona como personagem da "estória", do acontecimento de que ela se tomau parte central. Com a vantagem de o acontecido poder acontecer, por intermédio da TV, vezes sem conta.

Quando a televisão mostra um acontecimento como a derrocada das torres gémeas, por exemplo, assistimos aquilo a que podemos designar como a coincidência entre a narrativa e a acção. Isto é, o tempo do acontecimento, o tempo da informação e o tempo de leitura ou do espectador coincidem? .

2 Vinat, Lorenzo, Manipulación de la informatión televisiva, Edición Paidós, Barcelona, 1995, p. 150. 
Mas quando, posteriormente, o tempo da emissão, embora ainda em directo, já não é o do acontecimento, mas o da sua repetição ${ }^{3}$ até ao infinito, o efeito do processo comunicativo, mais do que informar, visa emocionar, provocar emoções no receptor das mensagens.

De uma forma muito resumida e generalizante, o que às vezes acarreta alguns problemas, eis a lógica dominante na comunicação social dos nossos dias. Dito isto, pergunta-se: como é que as cidadãos e as instituições, em situações de risco, podem confiar em quem vive e deseja cenários de risco porque, camo as números bem demonstram, são essas situações que, aproveitadas convenientemente, proporcionam lucros chorudos ao fim do mês?

Emprimeiro lugar, a nosso ver, importa clarificar um ponto essencial: quem, numa sociedade democrática como aquela que habitamos, define que uma dada situação é de risco: especcialistas, dirigentes políticos, empresários, sindicalistas, quéumdireito do cidadão comm? Mais: que meios têm as jomalistas para confimar se as informações, avisas ou alertas dados por terceiros, mesmo que protagonizados por organizações ou pessoas credíveis, correspondem a situações de risco autênticas, verdadeiras, iminentes? E se tais dadas forem contraditadas aos jomalistas por atras fontes igualmente credíveis, deveo jomalista dar a informação e, com ela, correr o risco de alarmar as pessoas, porque a informação ao amular-se a si própria apenas criou uma controvérsia nova, ou, pelo contrário, deve optar por nada dizer ou escrever?

O risco, bem o sabemos, "tomou-se um conceito central no debate público e político", onde, como assinalam a este respeito Jenny Kitzinger e Jacquie Reilly mum estudo publicado em 1997 no European Jamal of Commuication - e ajja versão emportuguês está traduzida por "Ascensão e queda de notícias de risco" (Minerva Coimbra, 2000) , recorrendb a autores como William Adams, Friedman, Anders Hansen e Peter Sandman, traçam o seguinte cenário de acção: "grupos de pressão procuram promover campanhas mediáticas por medidas de segurança; cientistas queixam-se dos exageros das notícias; empresas e governo recorrem a comunicadores de risco numa tentativa de manter ou captar a confiança pública; enquanto os jomalistas reconhecem a sua atracção pela controvérsia científica e pelas divergências sobre riscos ${ }^{\prime \prime}$.

\footnotetext{
${ }^{3}$ Thws, Eduardo Cintra (2006, p. 52) define esta situação camo o "directo anacrónico", porque "a sensação do directo mantém-se não só porque o pressuposto da emissão é o regresso em simul tâneo a qualquer instante ao lugar do acontecimento, como porque continuam a coincidir o tempo de emissão e otempode leitura".

${ }^{4}$ KTIZNERR, Jenny, Rewry, Jacquie, (2000) - Ascensão e queda de notícias de risco, Minerva Coimbra, p. 11.
}

É evidente que vivemos numa "sociedade de risco", para recorrer à expressão das autoras do Glasgow Media Group, obcecados com acidentes, desastres ecológicos ou erros tecnológicos, mas, ao mesmo tempo, trocámos a conquista do Santo Graal pela lousca da etema juventude e celebração db corpo, pelo prazer incessante, pela vida transformada emnovela.

Ora, é no interior deste complexo emaranhado de sentimentos, comportamentos e opções, onde os interesses e estratégias das diversos actores está longe de ser coincidente, que se situa o epicentro do problema. o qual, como se verámuito sucintamente, poỏe suscitar maiores dificuldades a jusante que a montante.

Isto, porque se muma dada situação de risco os actores envolvidos nas operações de controlo, salvamento e comunicação actuam normalmente sob uma direcção única, coerente e perseguindo objectivos comuns, o mesmo não se pode dizer das estratégias noticiosas dos meios de comunicação, as quais actuam de acordo com códigos próprios, autónomas e que, emúltima instância, remetem para o público e para as audiências a legitimidade quanto às escollhas e respectivas estratégias informativas.

Acresce a estes aspectos, já de si agravados por uma feroz concorrência, a entrada em cena das novas tecnologias, muitas vezes empregues por não jomal istas, mas ajo trabalho acaba por influenciar os meios de comunicação social tradicionais.

Paralelamente, começa a ganhar uma crescente importância o recurso aos chamados jornalistascidadãos, expressão a meu ver muito imprecisa, camo impreciso e muito difuso é o trabalho que fazem e vendem. Seja como for, não esqueço que as primeiras imagens dos atentados no metro de Londres foram tiradas por telemóvel, assim como são de turistas em Puhket os fragmentos de filme que chegaram às principais cadeias de televisão.

Pintadb o cenário, enão dostante os interesses ou, melhor dizendb, as prioridades divergentes entre, por um lado, os jornalistas e as empresas para que trabalham, e, por autro, as responsáveis envolvidos na solução das situações de risco, penso que só há um caminho possível, independentemente das desvios que cada um possa, depois, fazer no desempenho da respectiva função.

Esse caminho é o da aberturra, confiança e vercade. Quanto menos informação os jomal istas tiverem, mais condiçães têm para especular. Sobretudo aqueles cujo trabalho é mais influente na opinião pública, porque entram em directo e contam, mostram e mantêm o acontecimento quente. O pior erro é passar uma informação que os jornalistas podem, por outros meios, confirmar que não é vercadeira.

Temos, portanto, à luz deste raciocínio, um primeiro papel, a meu ver absolutamente decisivo, que 
é o desempenhado pelas fontes qualificadas. Cumprida esta parte, a responsabilidade passa inteiramente para o ladb das jomalistas.

É aqui, lamentavelmente, que alguns problemas au desvios aparecem, finto da inexperiência, às vezes da ignorância, quase sempre resultado da concorrência entre empresas e directores de meios de comunicação social. Essa, como se sabe, é outra guerra, não raramente muito suja, e cuja primeira vítima, como se sabe, é a vercade.

Porque, no fundb, tudb tende a ser visto e tratado com inegável ligeireza dentro da lógica do entretenimento around the clock, esquecendo, camo dizia o antigo jomalista da CBS, Dan Rather, que se "o espectáculo é importante para o funcionamento da nossa sociedade, o seu sistema de valores não é o mesmo da informação" ${ }^{5}$.

\section{A catástrofe é um acontecimento de elevado potencial mediático}

Ha, ainda, atra característica que importa referir, porventura mais sensível e delicada do que as anteriormente apontadas, mas que a meu ver não pode ser escamoteada. Refiro-me, concretamente, à ânsia e desejo de protagonismo de alguns jomalistas, muitas vezes visível em diversas ocasiões, ao ponto de quase sobreporem a sua presença, opinião e imagem ao acontecimento que estão a cobrir.

Ocorreu-me trazer este aspecto à colação, quando li no flyer da organização do III Encontro Nacional de Riscos (Mafra, Portugal, 2006) a expressão "repórteres de catástrofe". Se a esta designação juntarmos a de "repórter de guerra" com que alguns jomal istas portugueses gostam de se apresentar, não dostante passarem alguns anos sem ir à guerra, isso remete-nos para uma ideia algo nebulosa quanto ao modo como o exercício da profissão é interpretado.

As designações que apontam, neste contexto, para o concei to db especial ista mais não são que uma forma inteligente do aumento do prestígio pessoal e, por arrastamento, quando é o caso, para a passibilidade de alargamento do seu mercado de trabalho. Como jomalista que fui ao longo de mais de 20 anos, quero dizer que percebo essa estratégia e o seu alcance, mas isso não me impede ter uma atitude crítica e de distanciamento face a essas mesmas designações e estratégias - ou deverei dizer marketing? - de afimação. Caso contrário, porque não vemos autros profissionais da informação assumirem-se, orgulhosamente, como "repórteres de acidentes de viação" ou "repórteres de cheias e inundações"?

${ }^{5}$ Mesurita, Mário, (2003) - o Quarto equívoco, o poder dos media na sociedade contemporânea, Minerva Coimbra, p. 228.
Não quero com isto negar a ideia da especialização. Aquilo que pretendo, dizer, reportandb-me ao caso concreto de Portugal, que é a real idade que mais nos interessa porque é nela que habitamos e onde a cobertura das situações de crise mais nos toca, é sublinhar as diferenças de atitude que os diversos profissionais envolvidos num acontecimento desta natureza têm, necessária e compreensivelmente, de assumir.

Sabendo que onde houver uma situação de crise haverá, natural e desejavelmente, jomalistas por perto, dando corpo ao que poderemos designar como uma união de factos contemporânea, tal relação implica uma exigência profissional recíproca. E da parte a quem cabe fornecer as informações exige-se um conhecimento aprofundado da lógica e das regras do campo mediático.

A razão é simples. Uma catástrofe ou uma mais simples situação de crise representa acontecimentos de enorme potencialidade mediática. Acresce, ainda, que o facto da sua ccorrência não estar na agenda e corresponder a algo inesperado, que rompe com a actualidade prevista e planificada, pode levar a que um ou vários órgãos de comunicação social enviem para os locais da notícia profissionais pouco experientes, insuficientemente preparados e, emalguns casos, sedentos de uns minutos de glória.

Observemos, embora sumariamente, a realidade portuguesa neste domínio: desinvestimento nos rearsos hmanos, visível, de resto, na substituição dos jomalistas mais experientes por jovens, a maior parte dos quais aceitando vínculos precários ou situaçães de autêntica proletarização, ao mesmo tempo que o clima de competição e concorrência conduz e propicia práticas profissionais altanente disatíveis e reprovéveis.

Dan Rather diz isto de uma forma mais crua: "O medo reina em todas as redaç̧ões. O medo de perder o emprego, o medo de ver a audiência baixar, o medo de ver as receitas publicitárias desaparecerem. . . O medo conduz-nos ao erro. Mas este medo é reforçado por um atro medb ainda mais forte. Nós, jomalistas, temos medo de ficar isolados. Temos medo de sermos os únicos a pretendermos ser virtuosos num mundo onde ninguém o é" ${ }^{\prime \prime}$.

É dentro deste quadro, general izadamente pintado a negro, que os técnicas envolvidos no planeamento e gestão de situaçães de crise têm de saber movimentarse e dar respostas, sendo certo que "não há uma perceepção inequívoca de quem está interessado em enfatizar o risco ou em o reduzi $r^{\prime \prime}{ }^{\prime 7}$, como referem Jenry Kitzinger e Jacquie Reilly no seu estudb sobre notícias de risco.

\footnotetext{
${ }^{6}$ Mescuita, Mário, idem, p. 232

${ }^{7}$ KHYINH, Jenny; Remry, Jacquie, q. cit. , p. 42
} 
O referido estudo, como se depreende deste pequeno trecho, introduz um outro olhar sobre a matéria, questionando-nos acerca do alcance e impacte do risco, consoante a sua apresentação tenha origem nos media ou nos especialistas. Por outras palavras, a apresentação e comunicação do risco está longe de ser algo absolutamente linear e pacífico. Já toolos assistimos, de resto, a casos de clara desdramatização e tentativa de desmontagem de notícias scbre situações de risco, por parte das mais diversos responsáveis de organismos oficiais.

A inversa, dir-se-á, tambémé verdadeira. au seja, que não faltam exemplos de nítido empolamento ou aproveitamento de casos sem que exista uma justificação plausível para a sua ampla noticiabilidade. A atenção desmesurada que há mais de um ano todos os órgãos de commicação social portugueses deram sobre a gripe das aves, como se a pandemia estivesse a chegar às "linhas de Elvas", é um exemplo que certamente todos recordarão.

Quer isto dizer, portanto, que a abordagem desta matéria, além de sensível, é muitas vezes complexa, atendendo às múltiplas variáveis em presença. Seja como for, é através de encontros e debates pluridisciplinares que se podem dar passos seguros, no sentidb de se encontrarem pontes entre os diversos actores. Porque independentemente da diversidade de funções e objectivos profissionais de cada um, é no aprofundamento do conhecimento do trabalho recíproco que pode começar a construir-se uma nova consciência profissional e cívica.

Não será fácil e, garantidamente, demorará o seu tempo. Porque essa nova consciência implica uma dimensão da responsabilidade, baseada numa confiança mútua. Porém, nesse dia todos os cidadãos confiarão mais nas notícias e também nas organizações. Mesmo quando estas lhes falarem, através dos media, de situações de crise ou de catástrofe. Porque, é bom ter presente, a sociedade da informação em que vivemos "assenta numa dependência das suas actividades face à nova tecnologia informacional e comunicacional, a qual por seu lado se baseia numa outra dimensão, igualmente fundadora das sociedades contemporâneas: a organização. A organização, que de resto pode ser também entendida e estudada como um fenómeno de informação e comunicação, marca hoje em dia todos e cada um de nós" ${ }^{\prime 8}$.

\section{Bibliografia}

Irrłco, Femando (2003) - Filosofia da Informação, uma introdução à informação como fundação da acção, da commicação e da decisão. Universidade Católica Portuguesa, Iisboa.

KTIZINAR, Jemry, REury, Jacquie (2002) - Ascensão e queda de notícias de risco. Minerva Coimbra.

Mesarma, Mário (2003) - O quarto equívoco, o poder dos media na sociedade contemporânea. Minerva coimbra.

Tores, Eduarob Cintra (2006) - A tragédia televisiva: um género dramático da informação audiovisual, Imprensa de Ciências Sociais, Iisboa.

VIAMR, José R. (2000) - Redacción periodística para lageneración digital. Editorial Universitas, Mbdrid.

\footnotetext{
${ }^{8}$ Irrhro, Femando, (2003) - Fillosofia da Informação, uma introcução à informação como fundação da acção, da comunicação e da decisão, Universidade Católica Portuguesa, Lisboa, 2003, p.93
} 